LA-5927-MS

Informal Report

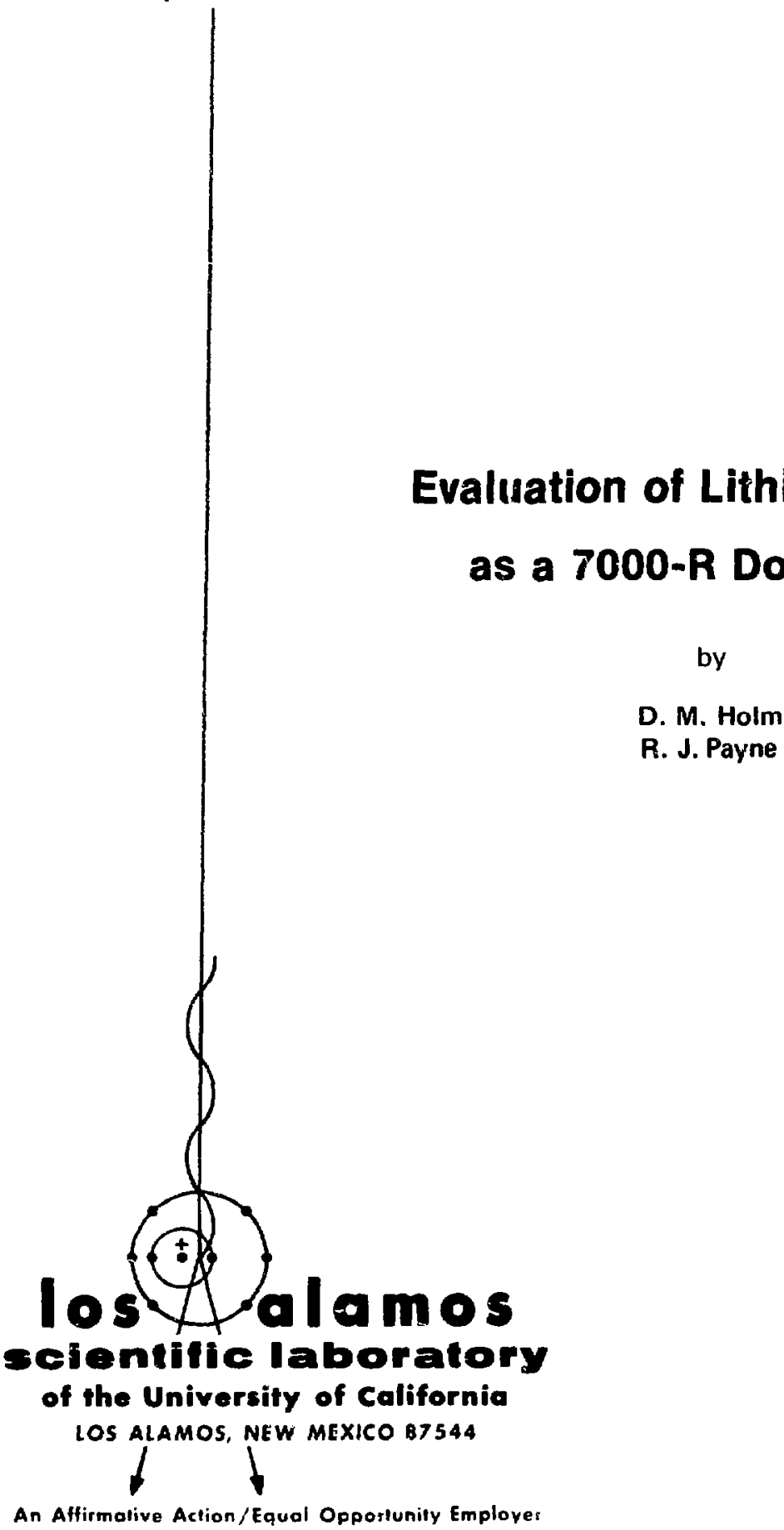

D. M. Holm

R. J. Payne
UC-48

Reporting Date: March 1975 Issued: April 1975

\title{
Evaluation of Lithium Borate as a $7000-R$ Dosimeter
}


In the interest of prompt distribution, this report was not edited by the Technical Information staff.

Work supported by interayency Agreernent No. 12.16.6.12 (VS) FY 1974 and Memorandum of Understanding (ERDA.APHIS) R.S.3167. LA.SL Reimbursable Project No. R209.

Printed in the United Siuties of America Avalable from National Technical Information Service

US Department of Commerce

5285 Port Royal Road

Springfiold, VA 22l5!

Price Printed Copy \$4.00 Microfiche \$2.25

This report was prepared an an accuusi of wart sponoured

b) The I nuted slater Gavernment. Neithur thr l'niled States

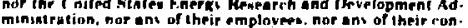

tructors, subeontractors. or thesr emploven, makes ans.

warrant e expreak or implied, of asumen any lezal liabilits of

responsibilits for the acruracs. complelenesk. or unelulness of

ant infurmusion. epparatus. produet. of orucerex disclosed, or

rifhin. 
- NOTICE

This peport was prepired as an eccount of work sponsisred by the United States Government. Netther the United States nor the United States Energy Resetarch and Davelopment Administration, nus any of their tmpluyecs, nor any of their contractiss, subcontractors. of their employees, makes any tharanty, cipress or jmplied, of assumes ans lezilt Liability of responsibility for the sccuracy, complituness or usefulness of any information, appasatus, product or process disclosed, or represents that its use would no infringe privately owned rights.

EVALUATION OF LITHIUM BORATI: AS A 7000-R DOSIMETER

$\mathrm{b} \dddot{r}$

D. M. Holm and R. J. Payne

\section{ABSTRACT}

The Harshaw Model $2271 \mathrm{TL}$ Detector/Dosimeter system with lithium borate dosimeters was evaluated as a $7000-R$ dosimetry system. One hundred dosimeter cards having two dosimeters per card were irradiated up to ninety-eight times with $x$ rays from a $250-k e V$ (electron energy) GE $x$-ray machine. A twofold change in calibration was observed during the course of 98 irradiation cycles and a decrease in light output versus time lag between irradiation and reading was observed. The first card "failed" on the $36 \mathrm{th}$ cycle and only two cards survived to the 98 th cycle. All of the failures were due to damage of the Teflon packaging, causing the dosimeters to hang up in the readout or to move in their card. This system could be used for screwworm fly dosimetry but is not considered ideal.

\section{INTRODUCTION}

The screwworm fly eradication program is based upon the principle that female flies mat 2 only once, and if this mating occurs with a sterile male, no progeny will result. Therefore, large numbers of sterile flies are produced by the U.S. Department of Agriculture (USDA) and are released in screwworm f1y-infested areas so that essentially all matings are between at least one sterile fly. Under these conditions essentially no fertile eggs are laid. The factory-produced flies are irradiated in the pupae stage with $7000 \mathrm{R}$ of ${ }^{60} \mathrm{Co}$ or ${ }^{137} \mathrm{Cs}$ gamma rays and after a few days, flies emerge from the pupae stage and are released over the target area. Special precautions are taken to assure that all pupae have been irradiated: 1) a sma1l card is placed on each canister to identify the batch and time of irradiation, 2) a second entry is made on the card as the canisters are emptied, the elapsed time is recorded and required to be within certain limits for passage of the canisters, and 3) a small sample of pupae is withdrawn from each canister and subsequently tested for fertility as a final proof test. By the time the results of this final proof test are in, the flies have been dropped. Therefore, it was deemed desirable to have individual dosimeters on each canister of pupae to assure that it had received a steri1 izing dose. The Los Alamos Scientific Laboratory (LASL) was requested to look into possible dosimeters for this application. The most likely candidate was the Harshaw Model $2271 \mathrm{TL}$ Detector/Dosimet $\mathrm{r}$ Identifier with 1 ithium borate dosimeters. It had not previously been used in this application; therefore, it was decided to perform an evaluation experiment.

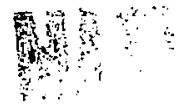


Materials and Methods

one hundred dosimeter cards were purchased from the Harshaw Chemical Company and the readout equipment shown in Fig. I was provided on loan by them. The experiments were carried out with the GE $(250-k \in V$ electron energy) $x$-ray machine at the Los Alamos Scientific Laboratory. The target had a low-energy $x$-ray filter (Thoraeus II; HVL, 2.6-mm Cu), so that most of the $x$-rays were about $125 \mathrm{keV}$. Frequent calibration was made with air ionization chambers and cross calibration was made to a ${ }^{60}$ Co source so that $x$ rays gave the same light output from the dosimeters as was obtained with $7000 \mathrm{R}$ of ${ }^{60} \mathrm{Co}$ gamma rays. Irradiation was accomplished by placing a stack of 50 dosimeters $26.5 \mathrm{~cm}$ from the $x$-ray target and irradiating then for about $21 \mathrm{~min}$.

The dosimeters were divided into two groups of 50 cards each, with six control cards in each group which were always placed in a central location in the stack (see Fig. 2). Less than $10 \%$ variation in reading was obtained between cards placed in different positions in the stack. While one stack of cards was being irradiated, the other stack was being read. A complete cycie consisted of irradiation with $7000 \mathrm{R}$

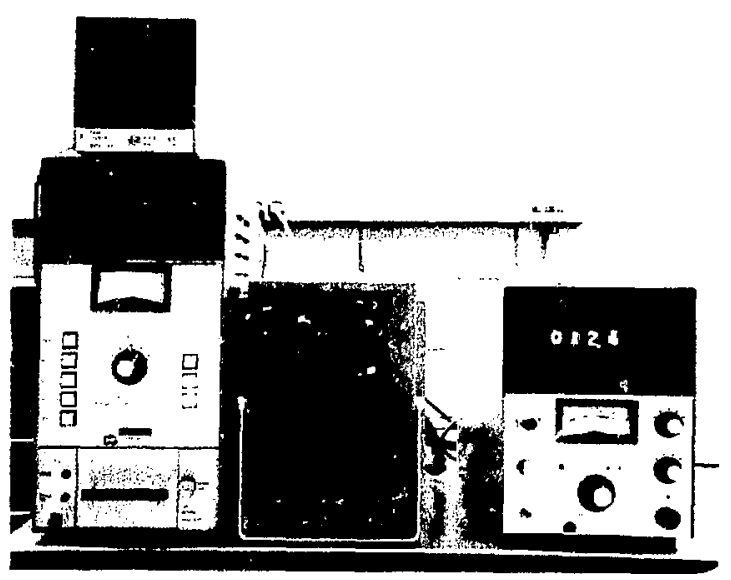

Fig. 1. The TLD automatic readout system loaned by Harshaw.

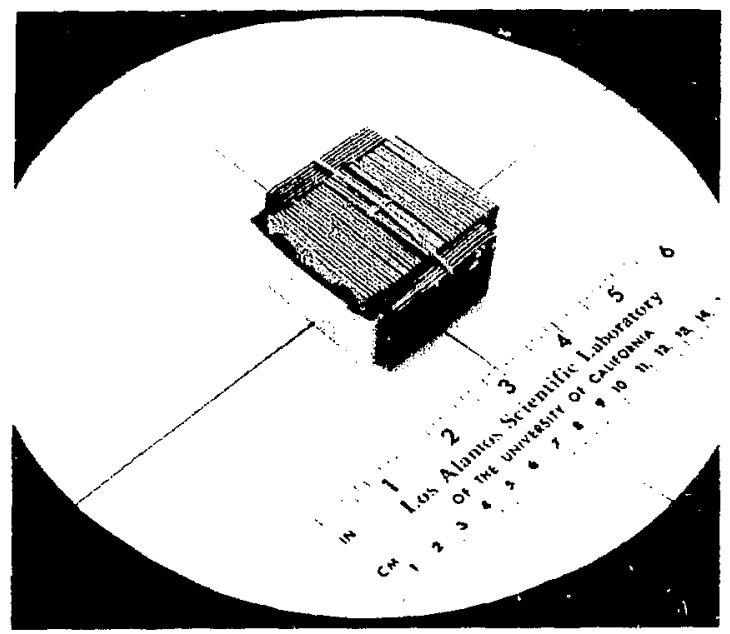

Fig. 2. The stack of 50 dosimeter cards ready for irradiation. Six "control cards" are together in the center.

and readout on the Mode1 2271 readout system. Readout consists of each dosimeter being heated for $10 \mathrm{~s}$ or $30 \mathrm{~s}$ both were used with no observable difference) and measuring with a photomultiplier the total amount of light given off. Background tests were made throughout the experiment to make certain that no residual dose remained on the dosimeters. The results from each reading were printed out on a teletype and the record consisted of the identification of the card, the total "charge" readings from an individual dosimeter, and a parity indication. The complete experiment was carried out in three months.

Results

While it was known that $T L$ dosimeters experience a change in reading versus time between irradiation and readout, it was not expected to be as great as was observed, so special precautions were not taken in the early part of the experiment to record the precise time between irradiation and readout. As a result, a rather large amount of scitter in the data was observed in the first 23 cycles (see Figs. 3 and 4). After the correlation was observed between a low 


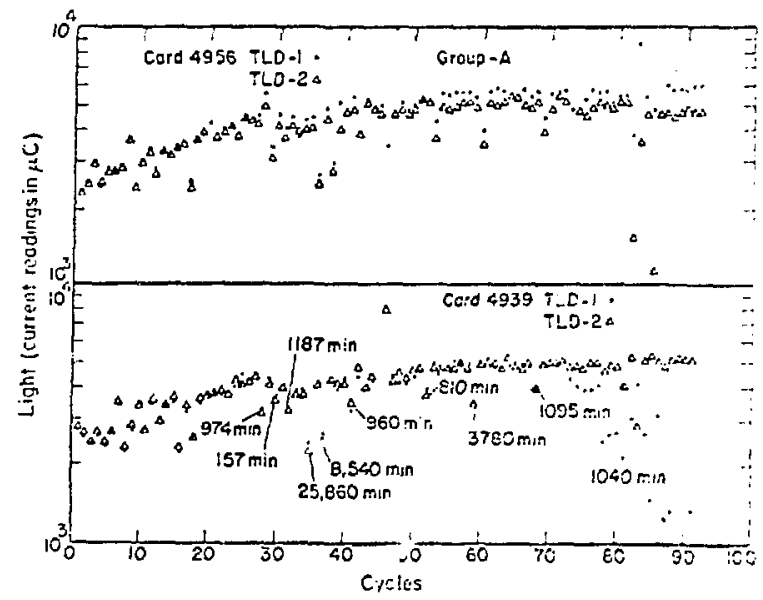

Fig. 3. Typical response of Group A control cards versus irradiation cycle. The elapsed time between the end of irradiation and the readout is indicated when greater than $45 \mathrm{~min}$. reading and a long time lapse between irradiation and counting, care was taken to record the time lapse.

Fig. 3 shows the response of two dosimeter cards in one group (A) and Fig. 4 shows the response of two cards in the other group (B). A twofold change in calibration during the course of the experiment is apparent. The reproducibility of the readings between $T L D-1$ and $T L D-2$ is quite consistent; i.e., if TLD 1 is high, it nor-

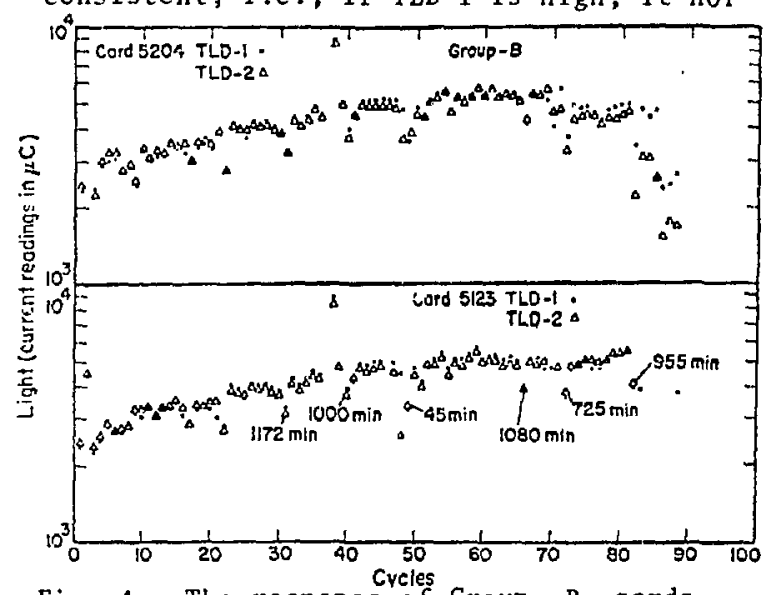

Fig. 4. The response of Group $B$ cards iersus irradiation cycle. A change in calibration of about $100 \%$ is observed. No correction factor has been applied to these data to compensate for elapsed time. mally remains high in all of the readings until damage to che card takes place and erroneous readings occur. An example of erroneous readings is evident starting in cycle 74 of card 4939 (Fig. 3) where the reading of TLD-I changed in its relative position to TLD-2.

Since the purpose of the experiment was to determine the suitability of the system for the screwworm fly dosimetry application, where the time between irraiiation and reading is small and relatively constant, the measurement of a shift in calibration wich time lapse was not considered of prime importance. However, since we were able to determine an approximate correction factor for various elapsed times, we have plotted the data in Fig. 5. The reader should be cautioned that there may be different correction factors with different irradiation cycles. If it is important to determine the elapsed time effect more precisely, a separate experiment should be designed. Our data are shown to illustrate the magnitude of the effect, ever though it is not important in our application.

Because of various experimental fac. tors, a dosimeter was seldom read within 20 min after the end of irradiation, and was frequently read as much as $45 \mathrm{~min}$ later. From Fig. 5 it can be concluded that an error of from 10 to $15 \%$ was incurred in

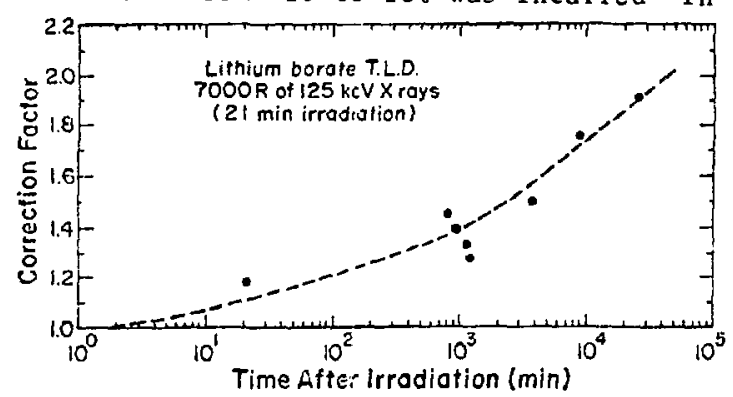

Fig. 5. The approximate correction factor versus elapsed time between irradiation and reading. To obtain the correct reading, multiply the observed reading by the correction factor corresponding to the proper elapsed time. The electron energy was $250 \mathrm{keV}$ and the average $\mathrm{x}$-ray energy was about $125 \mathrm{keV}$. 
this delay. In computing the data in Fig. 5 , these errors were taken into consideration; however, the raw data are plotted in Figs. 3 and 4 .

Three types of erroneous readings were encountered: 1) the previously mentioned time lapse effect, 2) a shift in the position of the dosimeter within its Teflon pocket and a subsequent misalignment of the dosimeter and the readout mechanism [an example of this type of error is the data beyond cycle 69 on card 5204 in Fig. 4], and 3) malfunctioning of the readout in which the card would be hung up in the system and not obtain the proper readout cycle. This is typified by card 5204, cycle 38 , in Fig. 4 .

Fig. 6 shows the survival of the dosimeter cards as a function of irradiation cycle. The first card to malfunction occurred in the 36 th cycle and the next card in the 51st cycle. The rate of failure increased rapidly after the 50 th cycle.

Fig. 7 shows a bent dosimeter card with the two dosimeters in the transparent circles at the top and the binary coded decimal ( $B C D$ ) identification holes in the lower half of the card. The bend in the card probably resulted from a slight swelling in one of the dosimeter pockets (i.e., the Teflon-covered TLD chip), which caused the card to hang up and $j a m$ in the readout. Since the dosimeters bulge slightly beyond

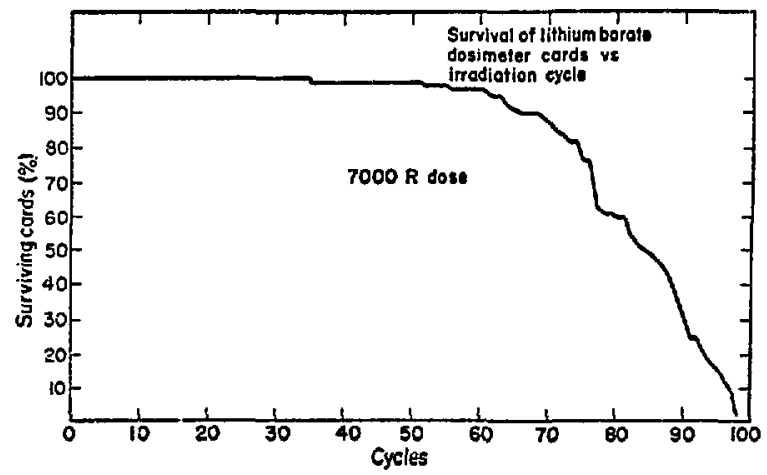

Fig. 6. A plot of the number of dosimeter cards that survive versus irradiation cycle.

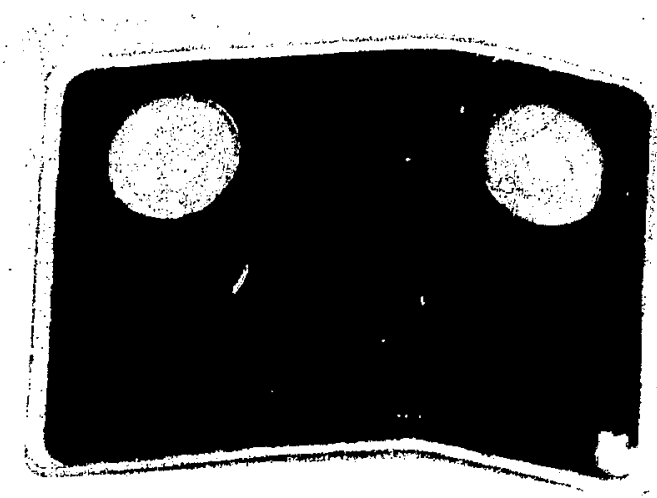

Fig. 7. The card receiver bends cards like this when they hang up in the mechanism. The two lithium borate dosimeters are at the top and the identification code holes are in the lower half.

the thickress of the card, most of the wear occurs on the dosimeter pockets. Fig. 8 shows the type of damage that results when the Teflon packaging wears through and creates a ragged edge which allows movement of the dosimeter and hang up of the card in the mechanism.

\section{I. PROBLEMS OF THE READOUT SYSTEM}

A. Card Receiver \#2271 R(lower left Fig. 1)

The basic problem is that it bends cards. During the first 21 runs, 28 cards were bent. The receiver was shipped back to Harshaw and wasn't returned until the

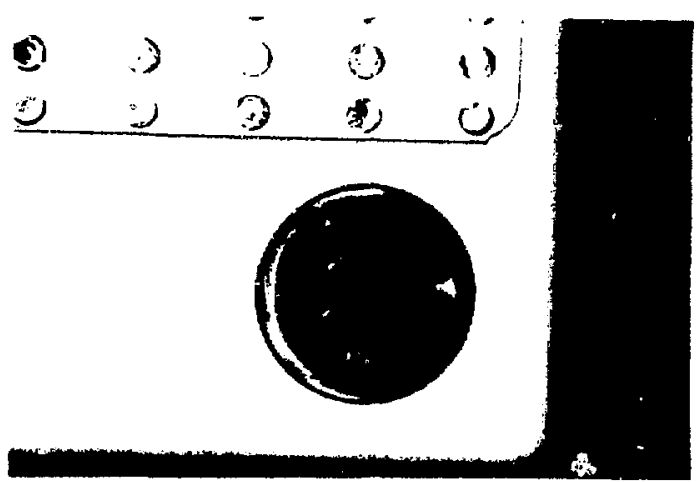

Fig. 8. An illustration of the type of damage in the dosimeter pocket that caused failure of a card to be read in the automated readout. The Teflon cover is worn through. 
start of run 86. Still a couple of cards were bent before experiment was completed. B. Card Loader \#2271 L (top left Fig. 1)

The tension cable mechanism caused general awkward loading and the handles would Erequently slip off the notch connection (bottom of Fig. 7 ). Because of the dosimeter bulge, the cards fed into the guillotine in a fan-like manner, thus causing an occasional jaming at the receiver. This problem was controlled by frequent positioning of the stack with one's fingers as the card advanced.

\section{Lamp Replacement (display panel of \\ Mode 1 2271)}

The replacement of lamps in the display panel required the following: removal of the display board from rear of the front panel, disconnect board from connector, unsolder lamp leads, install new lamp and solder leads to proper terminals, replace connector to display board, and install board in display panel. This is very time consuming and aggravating.

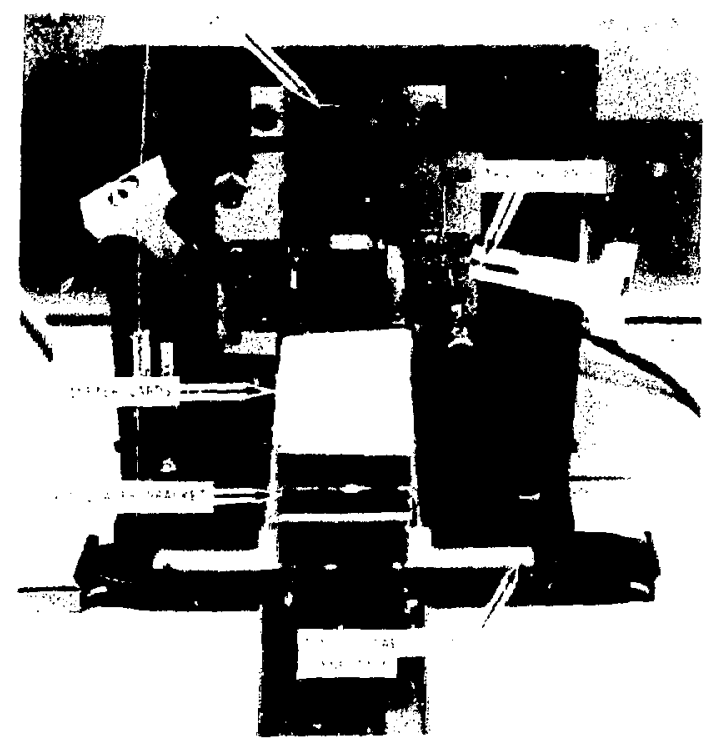

Fig. 9. A rear view of the card loader.

\section{TL Dosimeter Cards}

Apparently the "hot finger" causes the glue to seep out around the dosimeter pocket; this requires frequent cleaning of the cards. If an excess amount of glue remains on the card, it will cause the card to drag from $t$-bar to $t$-bar, and result in a "fault" indication, if out of position. In clearing the dosimeter card, the reading is generally lost.

After about 35 cycles, it was observed that the Teflon dosimeter pockets started to wear out, causing dosineter chips (1ithium borate) to protrude out of the pocket and jam. Sometimes the pockets were swelled enough to cause cards to drag and inisalign as they gravity-fad through the readout. This, in turn, caused numerous cardfault indications and stopped the cycle and frequently resulted in the loss of data.

\section{E. Clear Button}

Due to the amount of identification failures and card faults this "clear" button was used frequently, and its location on the rear of the TL detector was found to be inconvenient.

F. High-Voltage Failure

The high voltage tailed to come on because the H.V. relay (reed relay) \#K805 failed to operate. Resistor R833 was the wrong value $(3.3 \mathrm{k} \Omega$ ) and was replaced with a 500- $\Omega$ resistor per Harshaw approval. No further problem occurred with the high voltage.

G. T.L. Detector \#2271

As the experiment proceeded, "card fault" indications became more frequent, although the dosimeter cards appeared all right. The use of the "clear" button to advance the card would result in the loss of one TLD reading and often the loss of both.

After about cycle 70 , the machine continued to operate in an unreliable manner. "Card fault" Iights appeared more frequent$1 y$ and I.D. "failures" began to plague the operation. With I.D. failures, the card 
has to be released with the "card release" switch which requires opening the front panel.

The operation of the system finally came to a halt when the JL detector failed to start. A Harshaw technician worked on the problem several hours and reported finding that the "mother board" had a highresistance short on pin \#6. The short was cleared by removal of excess solder. This cleared the erroneous indications and the IL detector system functioned properly for the remainder of the experiment.

H. Card Release Switch

This switch would be more convenient to the operator if located on the front of the pane 1 .

\section{III . RECOMMENDATIONS AND CONCLUSIONS}

The dosimeter cards purchased from Harshaw had not been selected for uniformity in their response and $10 \%$ variation in calibrations between individual cards and dosimeters within a card was common. How ever, these differences remained quite constant in the course of the experiment indicating that the error was probably due to the amount of material in each dosimeter. Thus, selection of dosimeters could decrease the scatter of data points. In the USDA application, a plus or minus $10 \%$ variation in the readings could probably be tolerated.

The effect of lapsed time between irradiation and reading would not be serious in the USDA application and the change with calibration as a function of irradiation cycle could be taken care of with a calibration curve. Indeed, it might be possi- ble to reclaim dosimeters from used cards which would hold their calibration, as indicated by the plateau beyond cycle 50 .

It appears that the dosimeters could be used for up to 50 cycles without undue loss or errors in reading. The problems encountered in the automatic readout system were mostly aggravating, and would be minimal with serviceable cards, having less than 50 irradiation cycles. As indicated in the text, none of the problems in the readout were of a fundamental nature that could not be corrected. However, to assure that they were corrected, it is recommended that a service contract be an integral part of the purchase of cards and that Harshaw provide the readout service. The USDA could pay for the dosimetry service on a pro rata basis, guaranteeing the Harshaw Chemical Company a minimum throughpl.t.

An alternate solution to the USDA's problem would be to institute process control tecliniques in which the dosage can be assured. The units at Mission, Texas, would have to be redesigned to use process control techniques. However, the Harshaw dosimeter card system could be used in the present system with only very small changes in procedures.

\section{ACKNOWLEDGMENTS}

We wish to thank Ogden S. Johnson of LASL, Group H-4, for his assistance in the irradiations and use of the $x$-ray machine; Roland $W$. Davis, Group $P-6$, for the ${ }^{60} \mathrm{Co}$ irradiations, and F. Morgan $\operatorname{Cox}$ of the Harshaw Chemical Company for the loan and maintenance of the readout system. 